\title{
Research Paper: Study on the Awareness of the Students of Azad University of Medical Sciences About Nutrition and Food Storing Stuff During Crisis
}

Ali Miri', Mahsa Hami², Abdollah Dargahi ${ }^{3}$, Mohsen Poursadeghiyan ${ }^{4}$, Mehrdad Farrokhi ${ }^{4 *}$, Reyhaneh Ivanbagha ${ }^{5}$, Mohammad Masood Khalesi $^{6}$

1. Department of Nutrition, School of Health, Zabol University of Medical Sciences, Zabol, Iran.

2. Department of Economic Development and Planning, Firoozkuh Branch, Islamic Azad University, Firuzkuh, Iran.

3. Department of Environmental Health Engineering, School of Health, Hamadan University of Medical Sciences, Hamadan, Iran.

4. Research Center in Emergency and Disaster Health, University of Social Welfare and Rehabilitation Sciences, Tehran, Iran

5. Department of Midwifery, School of Nursing and Midwifery, Ardebil University of Medical Sciences, Khalkhal, Iran.

6. Department of Basic Sciences, School of Rehabilitation Sciences, Iran University of Medical Sciences, Tehran, Iran.

Article info:

Received: 10 May 2017

Accepted: 20 Sep. 2017

\section{Keywords:}

Awareness, Nutrition, Storing foodstuff, Food safety, Disaster
Citation: Miri A, Hami M, Dargahi A, Poursadeghiyan M, Farrokhi M, Ivanbagha R, et al. Study on the Awareness of the Students of Azad University of Medical Sciences About Nutrition and Food Storing Stuff During Crisis. Health in Emergencies and Disasters Quarterly. 2018; 3(2):91-96. https://doi.org/10.29252/NRIP.HDQ.3.2.91

: https://doi.org/10.29252/NRIP.HDQ.3.2.91 


\section{Introduction}

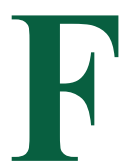

ood hygiene is considered as an essential principle in preventing human inflammation, infections, and diseases. Millions of people all over the world suffer from foodborne illnesses every year. This issue is known as a common problem across the globe. Food-borne illnesses are indicative of the spread of public health problems, both in developed and developing countries. However, these issues have a more significant impact on health and economics in developing countries [1]. The World Health Organization views diseases caused by food contamination as one of the most critical health problems in the contemporary world [2]. Factors commonly associated with the epidemic of foodborne diseases include improper food storage, contamination of tools, food from unhealthy resources, poor personal hygiene, and inadequate cooking [3], especially in times of crisis and disasters, these factors should be considered carefully.

Food hygiene is an issue in almost all natural and human-made emergencies; since people in such situations tend to leave their homes, food products are spolied, transportation system halts, and social structure of the society collapses. The emergence of food crisis is caused by factors such as bad climate, natural disasters, economic crisis, long-term wars, fire, lack of water, and a mixture of all these elements. The rate of the outbreak of such crises has increased since the 1980s; so that every year after 2000 the world has been faced with 50-80 food crises. Foodstuff hygiene during emergencies has a direct relationship with people's health. Diseases that are transferred by food can lead to destructive outcomes for public health. Using unhygienic food might cause death and illness of millions; therefore, hygiene (safety) of food needs particular attention [4-6].

One of the primary responsibility of the authorities is to plan, prepare, and predict the needs in the case of a crisis and further consequences. Supplying hygienic food and water for the people afflicted by disasters is one of the leading measures. Such preventive measured are highly efficient on nutrition condition of the public after outbreak of a crisis, term and extent of the crisis, and food production capacity in the afflicted area. Preventing, preparing for, and dealing with crisis and also supporting and rebuilding food supplies and empowering the population afflicted by the crisis is part of the responsibilities of states [7].

Human force and organizational factors determine how well an emergency crisis can be prevented or managed
[8]. Managing crises entails using health expert in different fields who have enough knowledge about working in such situations. The extent of preparation and awareness of these experts is a determinant factor in reducing the damages sustained due to improperly distributed food in the areas afflicted by the crisis [9]. To this end, the experts and authorities need to attend training courses on how to deal with the crisis.

Studies have demonstrated that educating People and increasing their awareness level plays a significant role in improving nutritional status [10]. A study by Unklesbay et al. reported that students who have passed foodrelated curricula have a very high level of awareness and attitude than other students, and even perform well [11]. The present study is an attempt to survey awareness level of nutrition and how to store foodstuff during crisis in students of the Azad University of Medical Science.

\section{Materials and Methods}

This cross-sectional descriptive study was conducted on students of the Azad University of Medical Sciences in 2016. The number of samples needed for each field was determined in 1350 person in both the genders. The selected students were from faculty of medicine $(n=317$ people), Paramedicine ( $\mathrm{n}=108)$, Nursing and Midwifery $(n=270)$, Health $(n=317)$, Dentistry $(n=257)$, and Pharmacology $(n=81)$.

The stratified random sampling method was performed about different genders and fields of study, i.e., six groups of health fields according to previous studies. The data collection tool was a researcher-designed questionnaire (with ten questions). The experts confirmed the content validity and reliability of the questionnaire and internal consistency method (Cronbach alpha coefficient of 0.80 ), respectively. The questionnaire comprised two sections; a demographic section (age, gender, educational level, and field of study) and another section with ten questions about the students' awareness on nutrition and food preservation during crisis. The questionnaire was designed in two sections; a-demographics and b-10 questions about the level of awareness. Regarding the level of awareness, the correct answer would score " 1 " and wrong answer would score "0". The collected data analyzed by SPSS version 21.0 (SPSS Inc., Chicago, IL), standard deviation, one-sample t-test, and Mann Whitney test were used.

\section{Results}

In this study, 1,350 (405 male and 945 female) students from the Azad University of Medical Sciences were 
Table 1. Mean score of awareness level of nutrition and how to store foodstuff in crises based on age groups

\begin{tabular}{|c|c|c|c|}
\hline Index & \multicolumn{2}{|c|}{ Age Group } & Sig. \\
\hline \multirow{2}{*}{ Awareness } & $19-23$ & $24-29$ & \multirow{2}{*}{0.325} \\
\hline & 175.48 & 159.58 & \\
\hline
\end{tabular}

studied. The selected students were from faculty of medicine 317 Person, faculty of paramedicine 108 Person, faculty of nursing and midwifery 270 people, and faculty of health 317 people, faculty of dentistry 257 people, and faculty of pharmacology 81 people. Table 1 lists the respondents' answers to the questions about nutrition and how to store food stuff during crisis.

With regard to the questions about the level of awareness, Standard Deviation (SD) and rate of the response were calculated. This rate for the questions 5, 5, 7, and 9 was less than 0.5 , and this figure for the rest of the questionnaire was higher than 0.5. Question no.7 (foodstuff after the settlement of the victims) had the lowest rate of response $(39.5 \%)$ and question no. 11 (The main side-effects of storing foodstuff in the unhealthy situation) had the highest rate of respondents (80.3) (Table 2). Afterward, a specific ratio was compared with a constant number, and it was speculated that the ratios were equal to 0.5 (the expected response rate in the case of random answering or an equal ratio of the individuals who were aware or not aware). It was observed that this hypothesis is not supported and, therefore, the respondents had enough knowledge to answer all the questions.

Additionally, the results demonstrated that mean awareness score, $\mathrm{SD}$, and variation range in the students about nutrition and storing foodstuff in crisis were 5.87, 2.02 , and 1-11, respectively. Taking into account that total awareness score $\geq 6$ was considered as the level of acceptable awareness. Based on this categorization, awareness of the respondents about nutrition and the way of storing foodstuff in critical condition was a little less than this level (Table 3).

Mann-Whitney U test showed that there was no significant difference between a male and female students about their awareness $(\mathrm{P}=0.667)$. Also, concerning the awareness level, the students were categorized into two groups of above the fourth year and below the fourth year of the program. Moreover, Kruskal-Wallis test indicated that there was a significant difference between the faculties regarding their level of awareness. Therefore, level of awareness was highest in the faculty of health and lowest in the faculty of pharmacology. Eventually, level of awareness was examined based on the age of the participants, and no significant difference was observed ( $\alpha=0.0 .5 ; \mathrm{P}=0.324)$. It is notable that mean score of awareness in the younger students was higher in comparison with elder students (Table 4).

\section{Discussion}

The results demonstrated that less than $35 \%$ of the students had good awareness about nutrition and food-stuff storage during crisis. BanaieGhahfarokhi et al. survived awareness of the experts of environment health-food hygiene about emergency situations with emphasis on Shahrekord's flood in 2012. Their results showed a significant difference in awareness of the participants before and after the training. Also, there was a significant relationship between education level, place of work, and level of awareness about foodstuff. However, they found no significant relationship between the level of awareness and age and work experience in clinics [9].

A study by Dargahi et al. on awareness and attitudes of the students in Kermanshah about food hygiene and safety reported that $46 \%$ of the students had excellent awareness, $48 \%$ had moderate awareness, and $4.5 \%$ had low awareness. There was no significant relationship between the students' awareness and attitudes about food hygiene and safety and other parameters such as age, education level, gender, and faculty [1].

Table 2. Frequency rate of awareness level of nutrition and how to store foodstuff in crises

\begin{tabular}{ccc}
\hline Variable & Frequency & Percent \\
\hline Good (6-11) & 472 & 35 \\
\hline Moderate (4-6) & 520 & 38.5 \\
\hline Low (0-4) & 358 & 26.5 \\
\hline & & $\begin{array}{c}\text { IIlealth in } \\
\text { Emergencies and Disasters (Oluarterly }\end{array}$
\end{tabular}


Table 3. Mean score of awareness level of nutrition and how to store foodstuff during crisis based on the faculties

\begin{tabular}{cccc}
\hline Faculties & N & Awareness Level & Sig. \\
\hline Medicine & 100 & 173.91 & \\
Paramedicine & 150 & 162.23 & 0.001 \\
Nursing & 250 & 179.31 & 216.89 \\
Health & 500 & 141.89 & 117.42 \\
Dentistry & 150 & 200 & \\
Pharmacology & 200 & \\
\hline
\end{tabular}

A study on high school students in the USA and students at the University of Missouri demonstrated that the participants had acceptable awareness about the transferrable disease by food [12].

A descriptive and cross-sectional study by Imani et al. titled 'Nurses' awareness about crisis management and the pertinent factors" on 250 nurses showed that only $3.2 \%$ of the participants had excellent awareness of crisis management, $16.6 \%$ had good awareness, $52.3 \%$ had moderate awareness, and $27.9 \%$ had low-level awareness. In addition, the level of awareness had a direct relationship with education level, type of work shift, participation in crisis plays, and membership in crisis committee [13].

Another descriptive and cross-sectional study by Vosoughi Nayari on 190 of the soldiers reported that $43 \%$ of the participant had good awareness, $46 \%$ had moderate awareness, $11 \%$ had low awareness, and 50\% had neutral attitudes toward health measures in crises. There was no significant difference among the participants regarding readiness and awareness about crises based education level and age $(\mathrm{P}=0.05)$ [14]. Regarding the questionnaire, the highest level of awareness (80.4\%) was obtained about the side-effects of storing foodstuff in unhygienic condition, and the lowest level of aware-

Table 4. Student's awareness level of nutrition and how to store foodstuff in crisis (one-sample t-test)

\begin{tabular}{|c|c|c|c|c|}
\hline Questions & Awareness & No-Awareness & SD & Sig. \\
\hline $\begin{array}{l}\text { What type of food would you recommend during } \\
\text { the early hours of crisis? }\end{array}$ & 681 & 669 & 0.502 & 0.001 \\
\hline $\begin{array}{l}\text { Which one of the following recommendations are } \\
\text { not suitable in crisis? }\end{array}$ & 711 & 639 & 0.497 & 0.001 \\
\hline $\begin{array}{l}\text { Which one of the following recommendations are } \\
\text { not suitable in crisis? }\end{array}$ & 735 & 615 & 0.493 & 0.001 \\
\hline $\begin{array}{l}\text { Which are the main foods supply the nutritional } \\
\text { needs of the survivals in crisis afflicted regions? }\end{array}$ & 749 & 601 & 0.477 & 0.001 \\
\hline $\begin{array}{l}\text { How long (minutes) the food must be boiled to } \\
\text { ensure it is safe for eating? }\end{array}$ & 617 & 733 & 0.684 & 0.001 \\
\hline $\begin{array}{l}\text { How long (minutes) vegetables should remain in } \\
\text { solution before eating? }\end{array}$ & 603 & 747 & 0.492 & 0.001 \\
\hline $\begin{array}{l}\text { After settling the displaced population, which } \\
\text { food stuff should be supplied on weekly bases? }\end{array}$ & 614 & 736 & 0.490 & 0.001 \\
\hline What do we mean by dry food stuff during crises? & 719 & 631 & 0.499 & 0.001 \\
\hline $\begin{array}{c}\text { Should the sterilized milk with six months longev- } \\
\text { ity be consumed immediately after opening its } \\
\text { package? }\end{array}$ & 627 & 723 & 0.501 & 0.001 \\
\hline $\begin{array}{l}\text { Is sterilize milk a good replacement for pasteur- } \\
\text { ized milk given that it can be stored in ambient } \\
\text { temperature? }\end{array}$ & 748 & 602 & 0.487 & 0.001 \\
\hline $\begin{array}{l}\text { Decay of food stuff is a major consequence of } \\
\text { storing food in unhygienic situation? }\end{array}$ & 812 & 538 & 0.399 & 0.001 \\
\hline
\end{tabular}


ness $(36.8 \%)$ was obtained about the time needed to boil canned foods. In general, being aware of nutrition and food hygiene matters in crisis is a way to preserve one's health and prevent the transfer of diseases. In short, 73\% of the participants had good-moderate awareness levels, which can be construed as a good level of awareness of the population under study.

Biglari et al. reported that the highest level of awareness was in the field of hygiene and the least was related to the field of radiology and laboratory sciences. In this study, the total number of participants was 360 . In the current study, the highest level of awareness of the faculty of health is consistent with the study of Biglari et al. [6].

\section{Conclusion}

The results demonstrated that the students at faculties of health and Nursing had the highest level of awareness and the students at faculties of Pharmacology and dentistry had the least awareness about nutrition and storing food stuff during crisis. Therefore, it is necessary to conduct training programs in the form of a workshop or the inclusion of a course in the curriculum regarding awareness about nutrition and storing food stuff during crisis.

\section{Acknowledgments}

This research was extracted from the first author's MSc. thesis in Department of Nutrition, School of Health, Zabol University of Medical Sciences, Zabol, Iran. The Authors thank the Islamic Azad University Tehran Medical Branch, Iran staffs and student for assistance.

\section{Conflict of Interest}

The authors declared no conflicts of interest.

\section{References}

[1] Dargahi A, Atafar Z, Karami A, Hoseini Ahagh MM, Zaebi Y, et al. Knowledge and attitudes of Kermanshah University of medical sciences students in the field of food hygiene and safety. International Journal of Pharmacy \& Technology. 2016; 8(2): 13877-90.

[2] Jahed GH, Golestanifar H, Vosoughi M, Pahlavanzadeh B, Dargahi A. [Survey on attitude and knowledge of food safety and sanitation among soldiers of Arak Malek- Ashtar Garrison (Persian)]. Food Hygiene. 2012; 2(6):91-8.

[3] Lynch M, Painter J, Woodruff R , Braden C. Surveillance for foodborne-disease outbreaks--United States, 1998-2002. Morbid- ity and Mortality Weekly Report. Surveillance Summaries 2006; 55(10):1-42. PMID: 17093388

[4] Eslami H, Marzban A, AkramiMohajeri F, Rezaei Z, Rafati Fard M. Students' knowledge and attitude of hygiene and food safety at Shahid Sadoughi University of Medical Sciences in Yazd, Iran. Journal of Community Health Research. 2015; 4(3):159-67.

[5] Miri A, Poursadeghiyan M, Baneshi MM, Biglari H, Yari AR, Khammar A. Study on attitudes of students of Islamic Azad University Tehran Medical Branch toward food safety, 2016. Electronic Physician. 2017; 9(5):4289-95. PMCID: PMC5498690

[6] Biglari H, Hami M, Yari A, Poursadeghiyan M, Farrokhi M. Awareness of medical students of gonabad university about nutrition \& food preservation in disasters. Health in Emergencies and Disasters Quarterly. 2017; 2(3):133-38. doi: 10.18869/nrip. hdq.2.3.133

[7] Farajzadeh D, Soofiabadi GH. [Surveying nutritional problems in Sepah during the war (Persian)]. Paper presented at: The Military Health Conference. 18-19 May 2002; Tehran, Iran.

[8] Vosoughi M, Jahed Gh, Asgari M, Dargahi Gh, Golestani far H, Parastar S. Investigation of knowledge and attitudes of students in Tehran University of Medical Sciences on Health actions in emergencies. Quarterly Scientific Journal of Rescue \& Relief. 2012; 4(2):43-51.

[9] Banaieh Ghafarokhi B, SeyedRashed J, Pishkar A, Khalili M, Karami MH, Kolahi M. [Surveying awareness of environment hygiene health about food stuff hygiene in crises with emphasis on Kermanshah Flood in 2012 (Persian)]. Paper presented at: The $16^{\text {th }}$ National Conference on Environmental Health. 1-3 October 2013; Tabriz, Iran.

[10] Zare H, Shojaiezadeh D. [Evaluation of education efficacy on proper nutrition knowledge and iron deficiency anemia in Mehriz city (Persian)] [MSc. thesis]. Tehran: Tehran University of Medical Sciences; 2001.

[11] Unklesbay N, Sneed J, Toma R. College students' attitudes, practices, and knowledge of food safety. Journal of Food Protection. 1998; 61(9):1175-80. doi: 10.4315/0362-028x-61.9.1175

[12] Dargahi A, Farrokhi M, Poursadeghian M, Hosseini ahagh M, Karami A. Evaluation of Functional Preparedness and Nonstructural Safety of different health units of Kermanshah University of Medical Sciences in coping with natural disasters. Health in Emergencies and Disasters Quarterly. 2017; 2(4):201-6. doi: 10.29252/nrip.hdq.2.4.201

[13] Imani E, HosseiniTeshnizi S, Tafrihi M, Alavi A, Jafari A, Badri $S$ et al. [Nurses' knowledge about crisis management and its related factors (Persian)]. Journal of Health and Care. 2011; 13(4):10-8.

[14] Vosoughi Niri A, Vosoughi Niri M, Golestani Far H, Pahlovanzadeh B, Savadpoor MT. Investigation of army soldiers readiness about health actions in critical circumstances. Case study: Malek Ashtar Military Garrison's. Health in Emergencies and Disasters. 2013; 1(1):77-87. 
